\title{
All-terrain vehicle-related injuries and deaths in Newfoundland and Labrador between 2003 and 2013: a retrospective trauma registry review
}

\author{
Holly Black, MD, BN*; Desmond Whalen, MD, BSc (Hons)*; Sabrina Alani, BSc*; Peter Rogers, MD ${ }^{\dagger}$; \\ Cathy MacLean, $\mathrm{MD}^{\ddagger}$
}

\section{ABSTRACT}

Background: Injury and death involving all-terrain vehicles (ATV) has been reported in a number of Canadian provinces. The objective of this study is to describe the frequency, nature, severity, population affected, immediate health costs, efficacy of related legislation, and helmet use in ATV related injuries and deaths in Newfoundland and Labrador (NL).

Methods: A retrospective review of injured or deceased ATV riders of all ages entered in the Newfoundland and Labrador Trauma Registry from 2003 to 2013 was conducted. Variables studied included demographics, injury type and severity, use of helmets, admission/discharge dates, and referring/ receiving institution. Data was also obtained from the Newfoundland and Labrador Center for Health Information (NLCHI) and included all in-hospital deaths and hospitalizations due to ATVs between 1995 and 2013.

Results: There were a total of 298 patients registered in the trauma registry, resulting in 2759 admission days, nine deaths, and a total estimated immediate healthcare system cost in excess of $\$ 1.6$ million. More males $(N=253,84.9 \%)$ than females $(N=45,15.1 \%)$ were injured in ATV related incidents, $t$ $(20)=7.12, p<.0001$. Head and thorax injuries were the most serious. $38.6 \%$ of patients were confirmed to be wearing helmets. Mean injury severity scores are as follows: head injury $(M=11, S D=9.51)$, thorax $(M=10, S D=8.3)$, abdominal/pelvis $(M=9, S D=7.62)$, upper extremity $(M=9$, $S D=8.53)$, other injuries $(M=9, S D=10.56)$ lower extremity $(\mathrm{M}=8, \mathrm{SD}=8.34)$, and spine $(\mathrm{M}=8, \mathrm{SD}=6.52)$.

Conclusions: This study describes ATV related injuries and deaths in NL. Information from this study may guide physician practice, public education, and future legislation.

\section{RÉSUMÉ}

Introduction: Des blessures et des décès liés aux accidents de véhicule tout-terrain (VTT) sont déclarés dans différentes provinces au Canada. L'étude visait à décrire la fréquence, la nature et la gravité des blessures liées aux accidents de VTT à
Terre-Neuve-et-Labrador (T.-N.-L.), de même que la mortalité, la population touchée, les coûts directs en soins de santé, l'efficacité des lois en la matière et le port du casque de protection.

Méthode: II s'agit d'un examen rétrospectif de dossiers d'utilisateurs de VTT de tous âges, morts ou blessés dans des accidents de ce type de véhicule, et inscrits dans le Newfoundland and Labrador Trauma Registry, de 2003 à 2013. Différentes variables ont été examinées, notamment des données démographiques, le type de blessure et la gravité des lésions, le port du casque, les dates d'admission et de sortie ainsi que les établissements d'origine et d'accueil. Des données ont également été obtenues du Newfoundland and Labrador Center for Health Information et elles comprenaient toutes les hospitalisations ainsi que tous les décès survenus à I'hôpital, attribuables aux accidents de VTT et enregistrés entre 1995 et 2013.

Résultats: Au total, 298 patients ont été inscrits dans le registre des traumas; les accidents se sont soldés par 2759 jours d'hospitalisation et 9 décès, ce qui a entraîné un total estimé de plus de 1,6 million de dollars en coûts directs pour le système de santé. Plus d'hommes ( $N=253 ; 84,9 \%$ ) que de femmes ( $N=45 ; 15,1 \%$ ) ont été blessés dans des accidents mineurs et majeurs de VTT $(\mathrm{t}[20]=7,12 ; p<0,0001)$. Les accidents les plus graves touchaient la tête et le thorax. Un certain nombre de patients, soit $38,6 \%$, portaient un casque. Le score moyen de la gravité des blessures s'établissait comme suit : le crâne ( $M=11$, écart-type $[\sigma]=9,51)$, le thorax ( $M=10, \sigma=8,3)$, l'abdomen et le pelvis $(M=9, \sigma=7,62)$, les membres supérieurs $(M=9, \sigma=8,53)$, d'autres types de blessure ( $M=9, \sigma=10,56)$, les membres inférieurs $(M=8$, $\sigma=8,34)$ et la colonne vertébrale $(M=8, \sigma=6,52)$.

Conclusions: L'étude a permis de décrire les différents types de blessure liés aux accidents de VTT et les décès qui en découlent à T.-N.-L. L'information ainsi obtenue peut imprimer une orientation à la pratique médicale, à l'éducation du public et aux lois futures.

Keywords: trauma, all-terrain vehicles, Newfoundland and Labrador, safety, education, public health

From the *Faculty of Medicine, Memorial University of Newfoundland, St. John's, NL; †Discipline of Emergency Medicine, Faculty of Medicine, Memorial University of Newfoundland, St. John's, NL and the $¥$ Department of Academic Family Medicine, Faculty Development Director at the College of Medicine, University of Saskatchewan, Saskatoon, SK.

Correspondence to: Desmond Whalen, Faculty of Medicine, Memorial University of Newfoundland, St. John's, NL; Email: desmondw@mun.ca 


\section{INTRODUCTION}

An all-terrain vehicle (ATV) is defined as a small fourwheeled motorized vehicle designed for use on various types of terrain. ${ }^{1}$ ATVs employ motorcycle-type engines, a straddle-style seat, handlebars for steering, and low-pressure tires suited for rugged terrain. ${ }^{2}$ ATVs have seen a steady increase in popularity, ${ }^{3-7}$ particularly as recreational vehicles, ${ }^{7}$ and are widely used in Newfoundland and Labrador (NL). ${ }^{8}$ In an effort to ensure rider safety, Service Newfoundland and Labrador created legislation regarding operating ATVs, including age regulations and the use of an approved helmet. The provincial legislation in NL was amended to be more stringent in May 2005. This kind of public health legislation has an important role in protecting the health of populations ${ }^{9}$ and theoretically should have a positive impact on safety. ${ }^{10}$

As compared with the United States, there is a relative paucity of literature in Canada regarding ATV-related injuries. Additionally, no descriptive study of ATV-related injury in patients of all ages exists for NL; only the pediatric population has been investigated thus far to our knowledge. To better inform ATV injury prevention interventions, this study aimed to describe the frequency, nature, severity, population affected, immediate health care costs, the efficacy of related legislation, and the use of helmets in ATVrelated injuries and deaths in the province of NL.

\section{METHODS}

\section{Data and data collection}

We used a retrospective study design and obtained Research Ethics Board approval from both the Eastern Health Research Proposal Approval Committee and the NL Health Research Ethics Authority. ATV accidentrelated data were collected from the Newfoundland and Labrador Trauma Registry from 2003 to 2013. The trauma registry included patients initially treated at or referred to the Health Sciences Centre (HSC), St. Clare's Mercy Hospital, or the Janeway Children's Health and Rehabilitation Centre. The HSC, located in the capital city of St. John's, is accredited by the Trauma Association of Canada as a tertiary trauma centre and is the main trauma referral centre for adults in NL (population 510,000). St. Clare's Hospital is the only other adult hospital located in St. John's.
The Janeway Children's Hospital, also located in the capital, is the only trauma referral centre for children in the province. Any patient who had an ATV-related injury or death and who was treated at one of the aforementioned centres between 2003 and 2013 was included in this study $(\mathrm{n}=298)$.

A registered nurse (RN), employed by the Eastern Health Authority to maintain the trauma registry, extracted data from the trauma registry upon request of the research team. No patient identifiers are recorded in the trauma registry, and therefore, the RN was blinded to any patient information. All patients who presented to an Emergency Department (ED) where the mechanism of injury was noted to be ATV related were included, from minor injuries to those who eventually succumbed to injuries in the hospital. The variables extracted from the trauma registry data included age, sex, helmet use, blood alcohol, injury date, admission date, discharge date, discharge status, and referring and receiving institutions. No individual charts were reviewed; accordingly, no standard extraction sheet was used. On review of the registry, blood alcohol levels were poorly recorded and were subsequently not analyzed. Patients who did not require admission and who were discharged from the ED were also included in this study.

Patients who were referred to the Adult Trauma Centre, St. Clare's Hospital, or Pediatric Trauma Centre from outside St. John's were identified, so they could provide insight into injuries occurring outside the urban centre. Patients who presented to a family physician or patients who were not referred to one of the three aforementioned hospitals from other areas of the province were not captured in this study. Data obtained from the Newfoundland and Labrador Centre for Health Information (provincial health information agency) included all ATV-related in-hospital deaths and hospitalizations between 1995 and 2013.

Any persons who died at the scene of an ATV-related crash were not included in this study. Data for those individuals would have gone through the provincial Office of the Chief Medical Examiner, and this information was not available to us.

\section{Statistical analysis}

Descriptive statistics were calculated using Microsoft Excel and SPSS. Comparisons of means were done as independent samples $t$-test and computed using 
SPSS software. To assess the effectiveness of amendments to safety legislation, the number of patients wearing helmets as noted in the trauma registry 2.5 years before and after the legislative amendment was compared. This time frame was used, as only data from 2.5 years prior to the legislation was available. A cost analysis was done using information obtained from the Division of Finance of Eastern Health and was calculated using the average cost of an acute care admission. The average cost of an emergency visit was added to each patient under the assumption that they had initially presented to an ED in the province. Data related to an intensive care unit (ICU) admission, surgical intervention, or out-of-hospital rehabilitation were not available from the trauma registry and therefore not included in our analysis. Our cost analysis is not meant to represent the overall economic burden but rather to illustrate immediate health care costs as a result of ATV-related incidents during the time frame. The formula used to calculate the cost per patient was the following:

\section{Cost per patient $(\$)$ in $2014=($ number of}

$$
\text { days in the hospital } \times \mathbf{\$ 5 7 4 . 5 0})+\mathbf{\$ 1 3 4 . 5 0}
$$

According to Eastern Health: 1) $\$ 574.50$ is the average cost of a stay in an acute care bed; and 2) $\$ 134.50$ is the average cost per visit to the ED.

\section{RESULTS}

\section{Patient demographics}

Between 2003 and 2013, 298 patients involved in ATVrelated incidents were recorded in the trauma registry. Of these 298 patients, nine died. The annual incidence and gender distribution of ATV-related injuries are shown in Figure 1. There were more males $(\mathrm{n}=253,84.9 \%)$ than females ( $\mathrm{n}=45,15.1 \%)$ injured in ATV accidents each year, $\mathrm{t}(20)=7.12, p<0.0001$. The patient ages ranged from 2 to 88 years with an average age of 31.6 (standard deviation $[\mathrm{SD}]=17.82$ ) years, and the mode was 16 years of age. The frequency of ATV-related injuries by age group is shown in Figure 2. Over the 10-year study period, $16 \%$ of those injured were under the provincial legal ATV operator age of 16 years.

Geographically speaking, $53 \%$ of the patients in the trauma registry who experienced an ATV-related injury or death initially presented to an institution outside St. John's.

\section{Safety behaviour}

Helmet use was unknown for $36.6 \%$ of the population studied. Helmet use was confirmed for $38.6 \%$ of the patients. Further, $24.8 \%$ of the patients were not wearing a helmet at the time of their injury. A breakdown of helmet use by year is illustrated in Figure 3 .

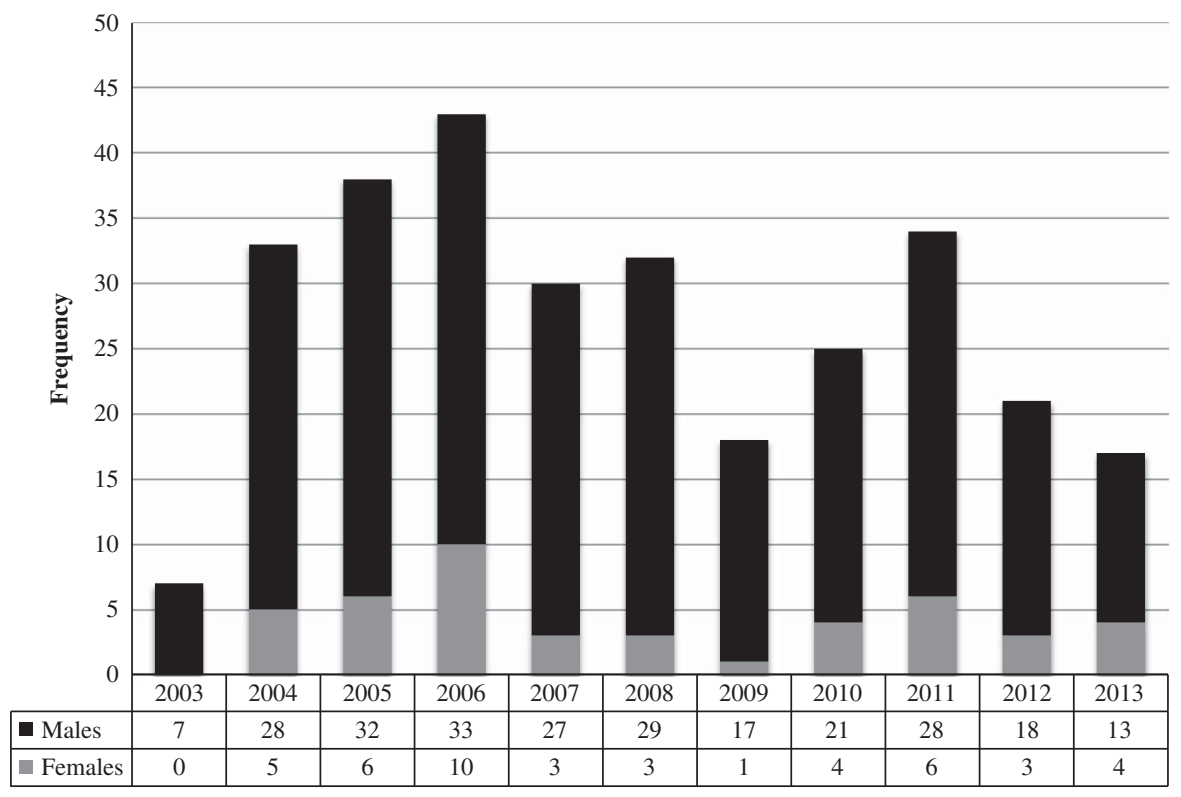

Figure 1. The annual incidence of ATV-related injuries between 2003 and 2013 according to the trauma registry that shows a bimodal distribution peaking in 2006 (43 cases) and 2011 (34 cases). The gender distribution was unequal, with more males than females injured. 


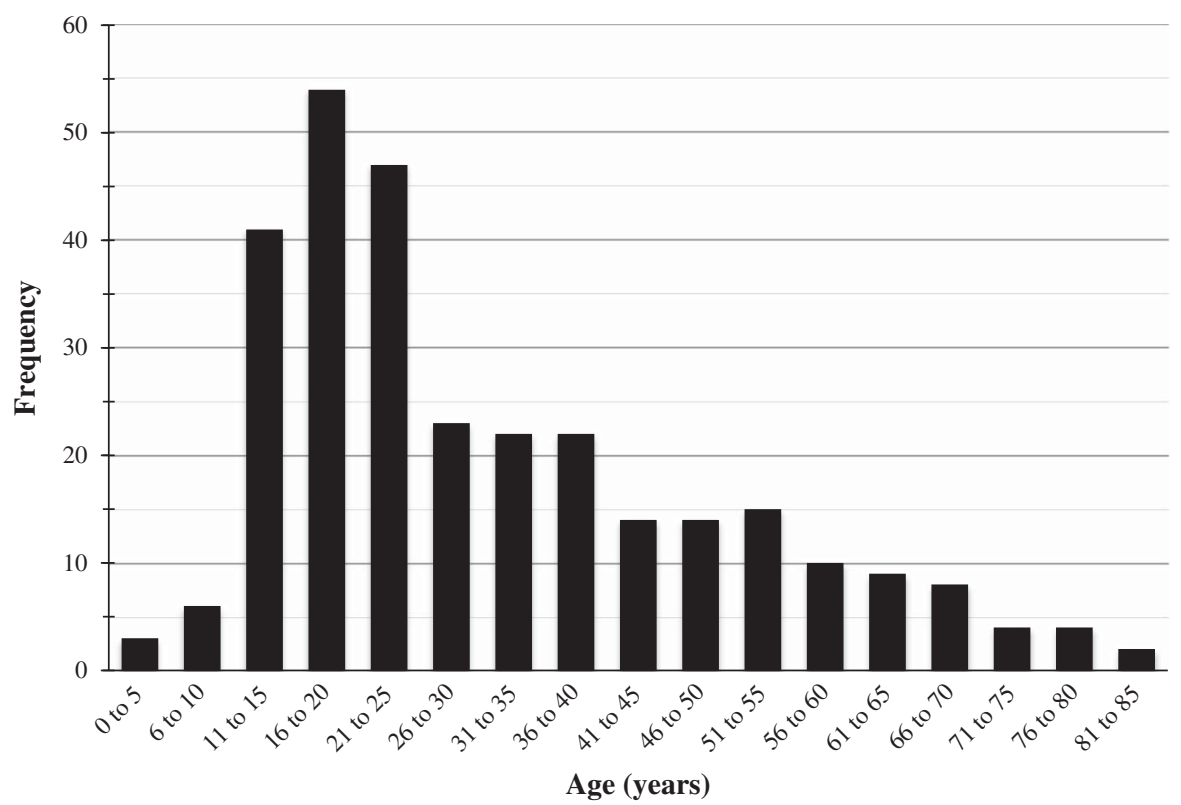

Figure 2. The frequency of ATV-related injuries in NL by age group between 2003 and 2013 according to the trauma registry.

In the 2.5-year pre-legislative amendment period, $45.45 \%$ of the cases used a helmet, and $47.54 \%$ used helmets in the 2.5 -year post-legislative amendment period $(\mathrm{t}[92]=0.19, p>0.05)$.

Of the nine deaths in our study population, only one person was confirmed to have been wearing a helmet. There were six deaths in which the patient was not wearing a helmet, and the use of a helmet was unknown for two deaths.

\section{Injury pattern}

The most common injuries were to the head and lower extremities, each of which was seen in $21 \%$ of patients. Injuries to the thorax and upper extremity were both observed in $15 \%$, followed by spinal injuries (12\%), abdominal/pelvic injuries (11\%), and other injuries (5\%) such as burns and superficial wounds. For all 298 patients, 29\% $(\mathrm{n}=87)$ had more than one body region involved. A breakdown of the frequency of injury types is shown in Figure 4.

Injury severity scores (ISS) were available for all but one of the patients in the trauma registry. The mean ISS was the highest for patients with a head injury (mean $[M]=11, S D=9.51$ ), followed by the thorax $(\mathrm{M}=10, \mathrm{SD}=8.3)$, abdomen/pelvis $(\mathrm{M}=9, \mathrm{SD}=$ $7.62)$, upper extremity $(M=9, S D=8.53)$, other injuries such as superficial wounds and burns $(M=9$, $\mathrm{SD}=10.56)$, lower extremity $(M=8, \mathrm{SD}=8.34)$, and spinal injuries $(M=8, S D=6.52)$. Figure 5 outlines the mean ISS according to the type of injury sustained. Further, no difference $(\mathrm{t}[149]=-1.22, p>0.05)$ existed in the ISS in the 2.5-year pre-legislative amendment period $(M=6.85, S D=6.17)$, as compared with the 2.5 -year post-legislation period $(\mathrm{M}=8.51, \mathrm{SD}=8.43)$.

\section{Immediate health care costs}

ATV injuries recorded in the trauma registry for the years 2003-2013 resulted in 2759 admission days. It was estimated that the immediate cost to the health care system because of ATV-related injuries between 2003 and 2013 was in excess of $\$ 1.6$ million. A breakdown of the estimated yearly cost to the system is shown in Figure 6.

\section{Long-term ATV-related trends according to the provincial health information agency, 1995-2013}

Between 1995 and 2013, the provincial health information agency reported a total of 1286 patients requiring a hospital admission, with a steady increase in the annual incidence of ATV-related hospitalizations. A simple linear regression indicated an increasing trend and predicted the number of hospitalizations each year $(\mathrm{F}[1,16]=23.87, p=0.0001)$. Based on this regression, the predicted values for 2014, 2015, 2016, and 2017 are 91, 93, 95, and 98, respectively. This trend is shown in Figure 7. 


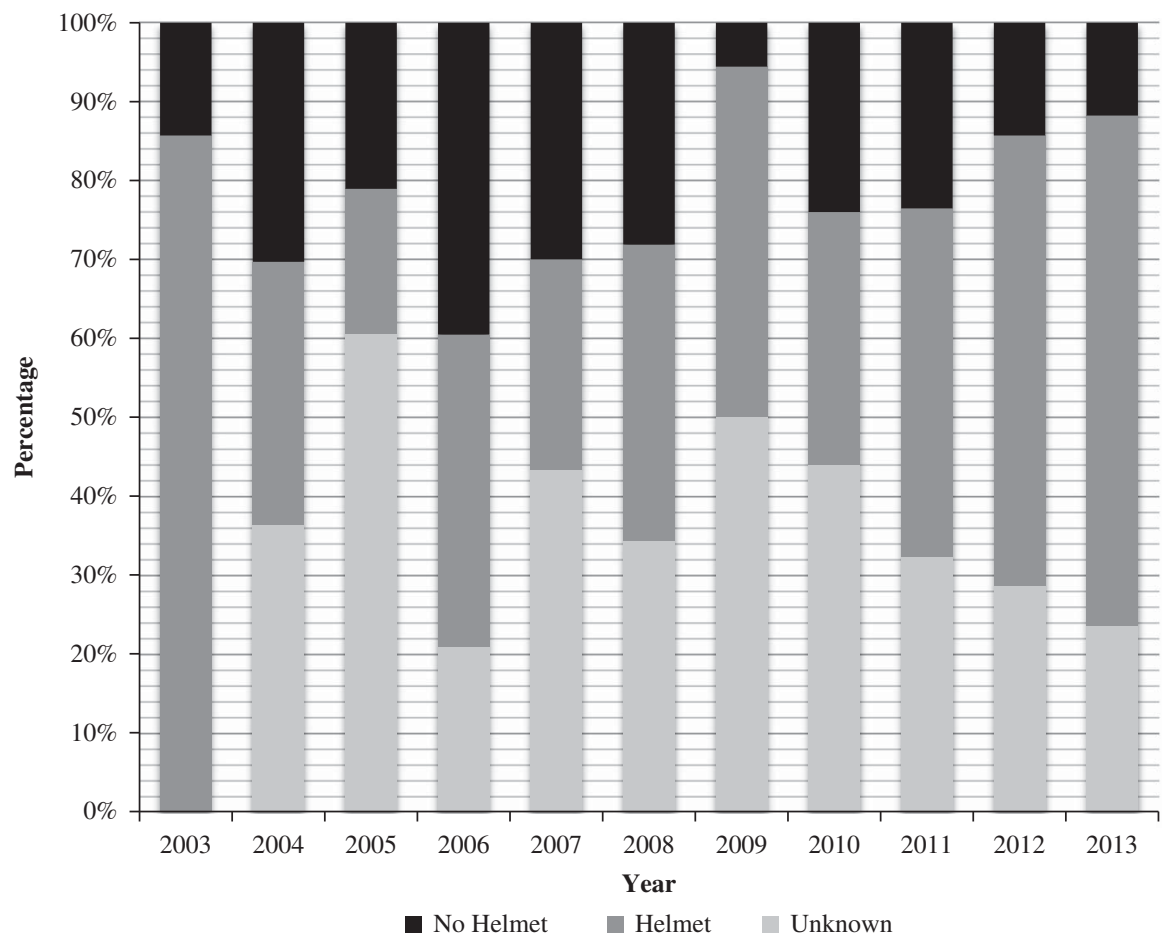

Figure 3. The annual incidence of helmet use among patients presenting with ATV-related injuries between 2003 and 2013 in NL.

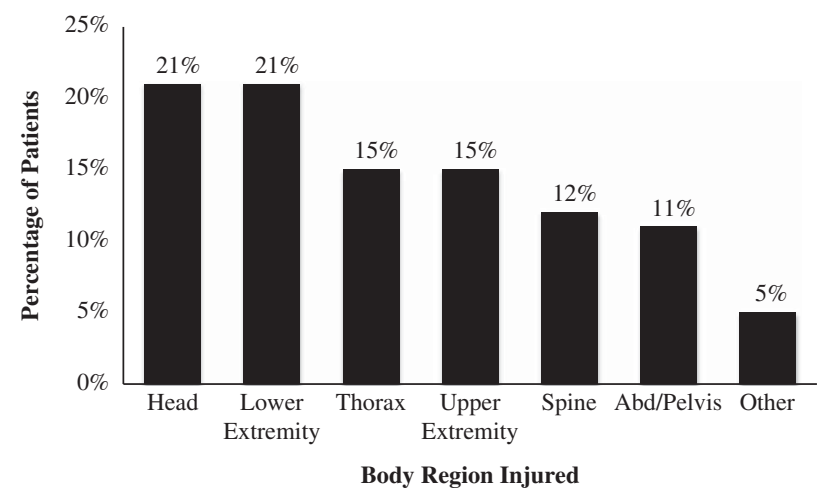

Figure 4. Percentage of patients with injuries by body region between 2003 and 2013 in NL.

\section{DISCUSSION}

Using data from the NL trauma registry (2003-2013) and the NL health information agency (1995-2003), this article describes the demographics, injury patterns, helmet use, hospitalizations, and immediate health care costs of ATV-related injuries in the province of NL.

Our findings demonstrated that males aged 16-20 years were the primary demographic injured and that is comparable to similar studies. A review of literature indicated that young males account for the majority of
ATV accident victims and should be the primary target for intervention. ${ }^{3,11-13}$ In addition, $16 \%$ of persons who were injured were under the age of 16 years. The data available to us did not differentiate between operators and passengers, so we could not indicate what proportion of injured persons under 16 years of age were in control of the ATV at the time of the incident. The current legislation in NL does not provide an age restriction for passengers on ATVs. Future research is necessitated regarding driver/passenger status and the possible risk of injury while riding as a passenger.

There was a general increase in the incidence of ATV-related injury hospitalizations between 1995 and 2013 according to the NLCHI (Figure 7). A bimodal distribution of frequency for ATV-related injury and death in the trauma registry was also discovered between 2003 and 2013, with peaks in incidence noted in 2006 and 2011 (Figure 1). Our results suggest that the incidence of ATV-related injuries was increasing until the introduction of amendments to legislation that made the penalties more stringent. After 2006, the incidence declined until a second peak was observed in 2011. This might be a result of increased ATV incident-related survival, conditioning to legislation, a possible decrease in enforcement, and changes in 
circumstances in which ATVs are used or in the economic environment/number of riders in NL. Considering these various factors and the limited data regarding the circumstances of injured riders, we believe more research is necessitated in this area.

Similar to other studies in which no more than $34 \%$ of subjects wore helmets, ${ }^{6,7,13-15}$ we found that $38.6 \%$ of patients were confirmed to be wearing a helmet at the time of their injury. Although legislation is believed to be a contributing factor to helmet use, our results suggest that there was no significant change in helmet use among injured riders following the introduction of more stringent legislation. The ineffectiveness of legislation alone has been found in other studies. ${ }^{6,7,13-17}$ There could be several reasons for this finding.

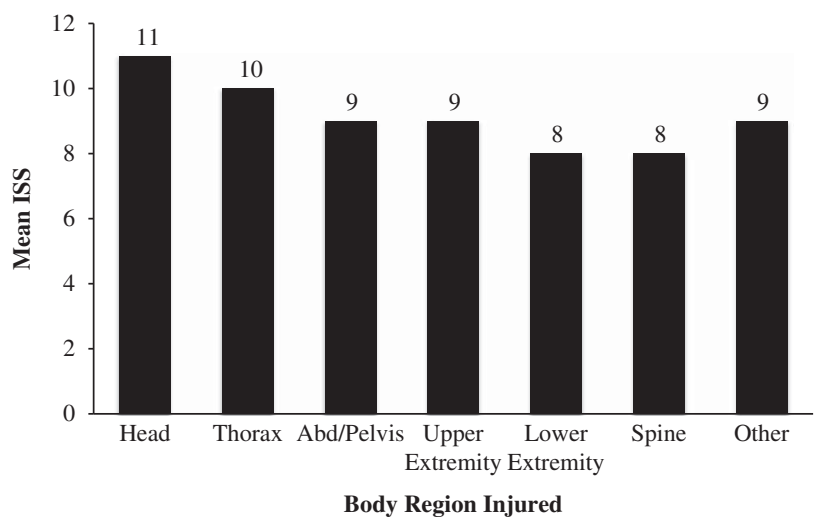

Figure 5. Mean ISS for patients by body region between 2003 and 2013 in NL.
Public knowledge of the laws in place might be lacking. The penalties for not complying with the legislation might not be enough to encourage helmet use. ATV riders might feel that they are less likely to be caught because of the off-road nature of their activity. Finally, enforcement of this legislation might be inadequate. These points further solidify the findings of others and our belief that in addition to legislation, an educational program is needed to raise awareness among riders. ${ }^{17-19}$ Furthermore, increased off-road patrolling and postinjury enforcement could be considered if violations are committed.

Of the nine deaths observed over the study period, six persons were not wearing a helmet, one was wearing a helmet, and two were unknown. The actual cause of death is not known for these patients, and causality cannot be inferred. Nonetheless, other studies have demonstrated an association between the lack of helmet use and increased morbidity and mortality. ${ }^{4,5,13,20-22}$

The most common injuries were to the head and lower extremity. The most severe injuries, as indicated by ISS, were to the head and thorax. Considering that head injuries were frequent and resulted in more serious injuries, more needs to be done to ensure that helmet use is maximized among riders. Furthermore, the frequency and severity of head injuries suggest that helmet use was unlikely, ineffective, or inappropriate in those patients for whom helmet use was unknown. Enforcement of helmet use is only part of the solution; research

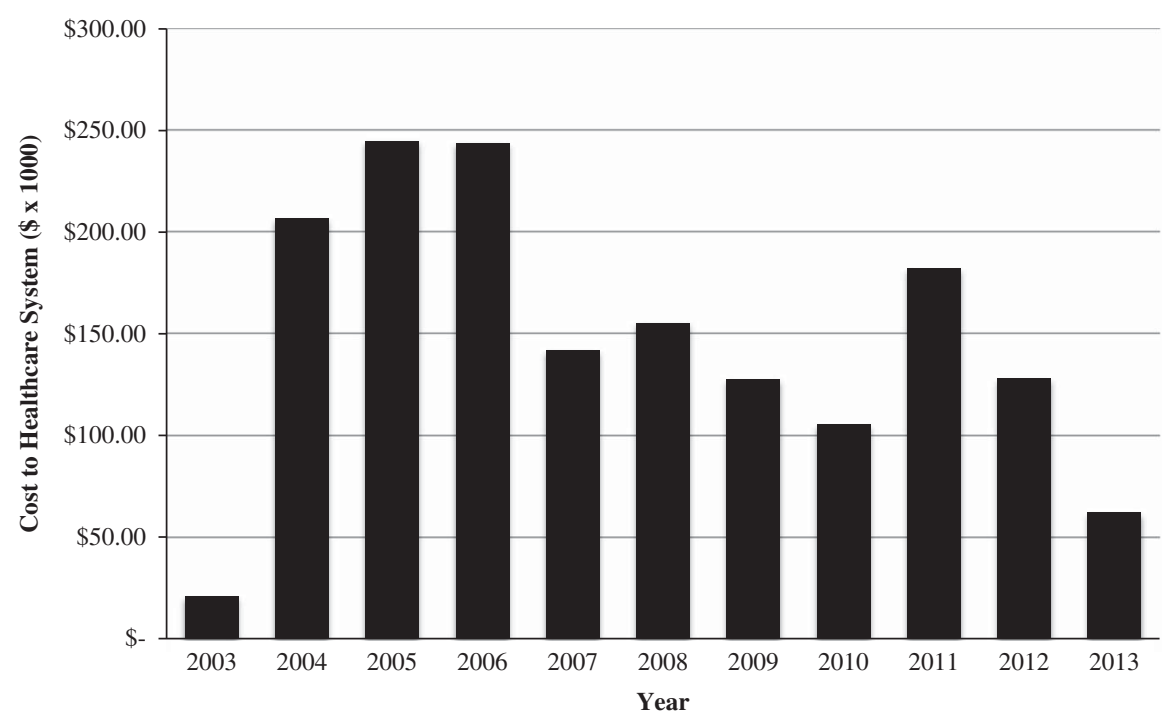

Figure 6. Annual economic burden because of ATV-related injuries between 2003 and 2013 in NL. The total cost to the system over the study period decade was $\$ 1,618,807$. 


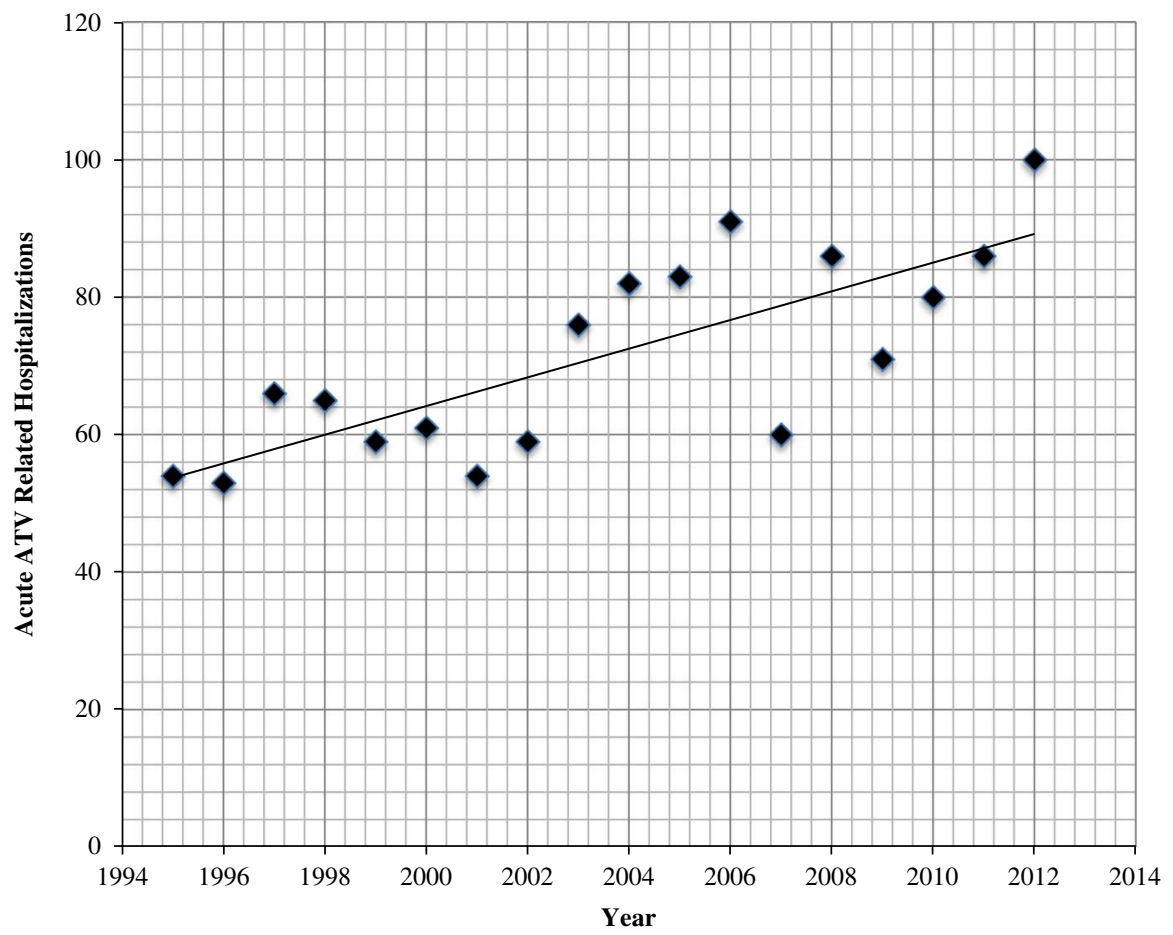

Figure 7. The annual incidence of hospitalizations because of ATV-related injuries between 1995 and 2013 in NL according to the provincial health information agency.

and education regarding proper helmet use might be needed. Our findings are consistent with other research showing that head and thorax injuries were the most severe in other jurisdictions. ${ }^{5,7,10-14,20,23,24}$

The legislation that was amended to impose stricter penalties in May 2005 had little effect in reducing the severity of injuries if considered in isolation. The ISS for the 2.5-year pre- and post-legislative amendment period showed no significant difference. Ideally, legislation should protect riders and decrease the number and severity of injuries sustained. In addition, given that $29 \%$ of patients sustained injuries to more than one body region, legislation could be more prescriptive around the use of safety equipment other than helmets.

An analysis of the available data showed that the immediate cost to the health care system for ATVrelated injuries between 2003 and 2013 was in excess of $\$ 1.6$ million. We found that the annual cost increased steadily up until 2006, after which a lower annual cost was observed. Although uncertain, this might be attributed to the legislative requirements put in place for ATV riders in mid-2005. The decline in the average cost to the health care system per year might also be because of missing data. Data related to ICU admission, surgical intervention, and rehabilitation were not available from the trauma registry; therefore, the cost analysis is likely underestimated. Another factor for the lesser cost calculated in this study could include the early discharge of patients to more suitable health care facilities or with community support such as rehabilitation, a model that is supported by Kosar et al. $^{25}$ This study was also limited to injuries that required tertiary trauma centre care and therefore excluded care administered at rural clinics and EDs. Provincial health information agency data suggested that there were more hospitalizations at a provincial level than was evidenced by the trauma registry. The exclusion of these rural areas might have caused an underestimation of the economic burden and frequency of ATV-related injuries. The prevention of ATVrelated injuries and death during the study period could have helped save over $\$ 1.6$ million to be reinvested in injury prevention education campaigns or other areas of the health care system. Along with the lack of helmet use, alcohol, ${ }^{3}$ riding as a passenger, ${ }^{26}$ and riding on public roads ${ }^{27-29}$ have been shown to be significant risk factors for ATV-related injuries and deaths. For the 298 injured people, blood alcohol levels were only recorded in the trauma registry for 26 people. No data existed regarding passenger status and type of terrain; we were 
unable to analyze the relationship between these potential factors and injury among our study subjects. Based on other literature, they are likely important areas for future research and legislative development.

Additionally, we acknowledge that the measurement of variables for only the 2.5-year pre- and postlegislative amendment period might not have been adequate. However, previous studies examined the effect of the legislation on bicycle helmet use during the 1-year post-legislation period giving precedence for our selected time range. ${ }^{30}$

A major physician role is providing health maintenance through education; this could be done at the individual patient level and more broadly by public awareness campaigns. Having a better understanding of the groups at risk, patterns of injury, and limitations in current public health measures would better enable physicians both to treat and educate ATV riders.

\section{CONCLUSIONS}

This study described ATV-related injuries and deaths in NL. Information from this study could guide physician practice, public education, and future legislation. Despite being aimed at some of the high-risk behaviours (i.e., helmet use and age) displayed by ATV riders in NL, the current legislation for the province appears to be inadequate regarding helmet use and the prevention of significant injuries and/or deaths. Furthermore, people under the age of 16 years continue to be injured, although it is illegal for them to drive ATVs. There is no specific legislation regarding carrying passengers or any mandated education for riders. The deficiencies in the current ATV legislation point to education as a potential adjunct to further strengthen the safeguards for riders.

Acknowledgements: HB and DW are co-first authors. We would like to acknowledge the Primary Healthcare Research Unit for help with the statistical analysis. We would also like to thank Dr. Lori Rogers for her guidance on manuscript preparation and editing.

\section{REFERENCES}

1. All-terrain vehicle. Merriam-Webster.com; 2015. Available at: http://www.merriam-webster.com/dictionary/all-terrain \%20vehicle (accessed April 19, 2015)

2. Rodgers GB, Adler P. Risk factors for all-terrain vehicle injuries: a national case-control study. Am $\mathcal{f}$ Epidemiol 2001;153(11):1112-8.
3. Krauss EM, Dyer DM, Laupland KB, Buckley R. Ten years of all-terrain vehicle injury, mortality, and healthcare costs. 7 Trauma 2010;69(6):1338-43.

4. Lord S, Tator CH, Wells S. Examining Ontario deaths due to all-terrain vehicles, and targets for prevention. Can 7 Neurol Sci 2010;37(3):343-9.

5. Pelletier JS, McKee J, Ozegovic D, Widder S. Retrospective review of all-terrain vehicle accidents in Alberta. Can 7 Surg 2012;55(4):249-53.

6. Sibley AK, Tallon JM. Major injury associated with allterrain vehicle use in Nova Scotia: a 5-year review. C7EM 2002;4(4):263-7.

7. Su W, Hui T, Shaw K. All-terrain vehicle injury patterns: are current regulations effective? $\mathcal{F}$ Pediatr Surg 2006; 41(5):931-4.

8. ATV Safety. Government of Newfoundland and LabradorService NL. Available at: http://www.servicenl.gov.nl.ca/dri vers/atvsafety/ (accessed April 19, 2015).

9. Martin R, Lo Dak, Wai A. Comparative national public health legislation. In: Oxford Textbook of Public Health, 5th ed. (eds. Detels R, Beaglehole R, Lansang M, Gulliford M). Oxford: Oxford University Press; 2011: 351-67.

10. Winfield RD, Mozingo DW, Armstrong JH, et al. All-terrain vehicle safety in Florida: is legislation really the answer? Am Surg 2010;76(2):149-53.

11. Brandenburg MA, Brown SJ, Archer P, Brandt EN Jr. All-terrain vehicle crash factors and associated injuries in patients presenting to a regional trauma center. 7 Trauma 2007;63(5):994-9.

12. Fonseca AH, Ochsner MG, Bromberg WJ, Gantt D. Allterrain vehicle injuries: are they dangerous? A 6-year experience at a level I trauma center after legislative regulations expired. Am Surg 2005;71(11):937-40; discussion 940-1.

13. McBride AS, Cline DM, Neiberg RH, Westmoreland KD. Pediatric all-terrain vehicle injuries: does legislation make a dent? Pediatr Emerg Care 2011;27(2):97-101.

14. Blecker N, Rhee P, Judkins DG, et al. Pediatric all-terrain vehicle trauma: the epidemic continues unabated. Pediatr Emerg Care 2012;28(5):443-7.

15. Dietz MJ, Lavender C, Emery SE, Clovis N, Shuler FD, Zuberi J. All-terrain vehicle-related orthopaedic trauma in North Central West Virginia: an 8-year review of a Level I trauma center. 7 Orthop Trauma 2012;26(7):e83-7.

16. Lynch JM, Gardner MJ, Worsey J. The continuing problem of all-terrain vehicle injuries in children. 7 Pediatr Surg 1998;33(2):329-32.

17. Ross RT, Stuart LK, Davis FE. All-terrain vehicle injuries in children: industry-regulated failure. Am Surg 1999 Sep; 65(9):870-3.

18. Williams RS, Graham J, Helmkamp JC, et al. A trial of an All-Terrain vehicle safety education video in a CommunityBased hunter education program. I Rural Health 2011; 27(3):255-62.

19. Wood A, Duijff JW, Christey GR. Quad bike injuries in Waikato, New Zealand: an institutional review from 20072011. ANZ 7 Surg 2013;83(4):206-10.

20. Carr AM, Bailes JE, Helmkamp JC, Rosen CL, Miele VJ. Neurological injury and death in all-terrain vehicle crashes 
in West Virginia: a 10-year retrospective review. Neurosurgery 2004;54(4):861-6; discussion 866-7.

21. Helmkamp JC, Aitken ME, Graham J, Campbell CR. State-specific ATV-related fatality rates: an update in the new millennium. Public Health Rep 2012;127(4): 364-74.

22. Merrigan TL, Wall PL, Smith HL, Janus TJ, Sidwell RA. The burden of unhelmeted and uninsured ATV drivers and passengers. Traffic Inj Prev 2011;12(3):251-5.

23. Anfuso A, Weinberger PM, McKinnon BJ. Pediatric allterrain vehicle related temporal bone fractures. Int 7 Pediatr Otorbinolaryngol 2012;76(2):202-5.

24. Bansal V, Fortlage D, Lee J, et al. A 21-year history of allterrain vehicle injuries: has anything changed? Am 7 Surg 2008;195(6):789-92.

25. Kosar S, Seelen HA, Hemmen B, Evers SM, Brink PR. Cost-effectiveness of an integrated 'fast track' rehabilitation service for multi-trauma patients involving dedicated early rehabilitation intervention programs: design of a prospective, multi-centre, non-randomised clinical trial. $\mathcal{7}$ Trauma Manag Outcomes 2009;3(1):1.

26. Unni P, Morrow SE, L Shultz B. Analysis of pediatric allterrain vehicle trauma data in Middle Tennessee: implications for injury prevention. 7 Trauma Acute Care Surg 2012;73(4 Suppl 3):S277-80.

27. Denning G, Jennissen C, Harland K, Ellis D, Buresh C. Allterrain vehicles (ATVs) on the road: a serious traffic safety and public health concern. Traffic Inj Prev 2013;14(1):78-85.

28. Keenan HT, Bratton SL. All-terrain vehicle legislation for children: a comparison of a state with and a state without a helmet law. Pediatrics 2004;113(4):e330-4.

29. Shulruf B, Balemi A. Risk and preventive factors for fatalities in all-terrain vehicle accidents in New Zealand. Accid Anal Prev 2010;42(2):612-8.

30. Parkin PC, Khambalia A, Kmet L, Macarthur C. Influence of socioeconomic status on the effectiveness of bicycle helmet legislation for children: a prospective observational study. Pediatrics 2003;112(3 Pt 1):e192-6. 